\title{
Inherited Nonsyndromic Ichthyoses: An Update on Pathophysiology, Diagnosis and Treatment
}

\author{
Anders Vahlquist ${ }^{1}$ (D) Judith Fischer $^{2} \cdot$ Hans Törmä $^{1}$ (D
}

Published online: 16 August 2017

(c) The Author(s) 2017. This article is an open access publication

\begin{abstract}
Hereditary ichthyoses are due to mutations on one or both alleles of more than 30 different genes, mainly expressed in the upper epidermis. Syndromic as well as nonsyndromic forms of ichthyosis exist. Irrespective of etiology, virtually all types of ichthyosis exhibit a defective epidermal barrier that constitutes the driving force for hyperkeratosis, skin scaling, and inflammation. In nonsyndromic forms, these features are most evident in severe autosomal recessive congenital ichthyosis (ARCI) and epidermolytic ichthyosis, but to some extent also occur in the common type of non-congenital ichthyosis. A correct diagnosis of ichthyosis-essential not only for genetic counseling but also for adequate patient information about prognosis and therapeutic options-is becoming increasingly feasible thanks to recent progress in genetic knowledge and DNA sequencing methods. This paper reviews the most important aspects of nonsyndromic ichthyoses, focusing on new knowledge about the pathophysiology of the disorders, which will hopefully lead to novel ideas about therapy.
\end{abstract}

\section{Key Points}

Ichthyoses are the phenotypic results of gene mutations which - one way or another-lead to an imbalance of stratum corneum homeostasis and skin barrier failure.

Depending on the type of ichthyosis, different severities of localized or generalized hyperkeratosis and scaling are seen, often accompanied by erythema, fissures, and erosions.

Usual histopathologic findings are variable degrees of epidermal hyperkeratosis, hyperproliferation, and-more rarely—skin inflammation and superficial epidermolysis.

Genetic testing to confirm the diagnosis and enable correct genetic counseling is becoming increasingly rapid, but also more complicated because of the multiple testing (multi-gene panels) and the interpretation of large datasets.

On the basis of new knowledge about the pathophysiology of different types of ichthyoses, novel and more individualized treatment options will hopefully soon become available.

\section{Introduction}

Ichthyosis is a descriptive term embracing all forms of chronic, extensive scaling and superficial roughness of the skin, often combined with xerosis, fissures, erythema, occasional pruritus, and-in certain rare forms- 
suprabasal epidermolysis. The phenotypic expression of these monogenetic disorders can be seen only in the skin (nonsyndromic ichthyosis) or in combination with other organ involvements (syndromic ichthyosis) [1].

This review will focus on three types of nonsyndromic ichthyosis where new knowledge has led to a change in paradigms concerning pathophysiology, diagnosis, and treatment: ichthyosis vulgaris, autosomal recessive congenital ichthyosis (ARCI), and epidermolytic ichthyosis. Only when appropriate for the discussion will X-linked recessive ichthyosis and a few other syndromic disorders be mentioned, particularly in the context of differential diagnosis in infants.

Ichthyosis vulgaris, which shows semi-dominant inheritance, is almost never congenital, affects predominantly the extremities (Fig. 1a), and the skin symptoms typically fluctuate in response to climate changes (worse in cold and dry weather). It is the most common form of ichthyosis with an incidence of up to $1 / 100$ [2], more than 10-fold higher than for X-linked ichthyosis (1/2000 males), and 100-300 times higher than for ARCI $(1 / 100,000)$ and epidermolytic ichthyosis $(1 / 300,000)$.
Fig. 1 Examples of ichthyosis subtypes discussed in the text. a Ichthyosis vulgaris on the lower extremity associated with $F L G$ mutations. b Generalized autosomal recessive congenital ichthyosis (ARCI); lamellar ichthyosis due to truncating mutations in TGM1.

c Pleomorphic ARCI; focal ichthyosis on the trunk due to point mutations in TGM1 rendering the enzyme inactive only in areas with higher skin surface temperature (so-called bathing suit ichthyosis).

d Epidermolytic ichthyosis due to a dominant negative KRT10 mutation (pictures from the files of $\mathrm{AV}$ )
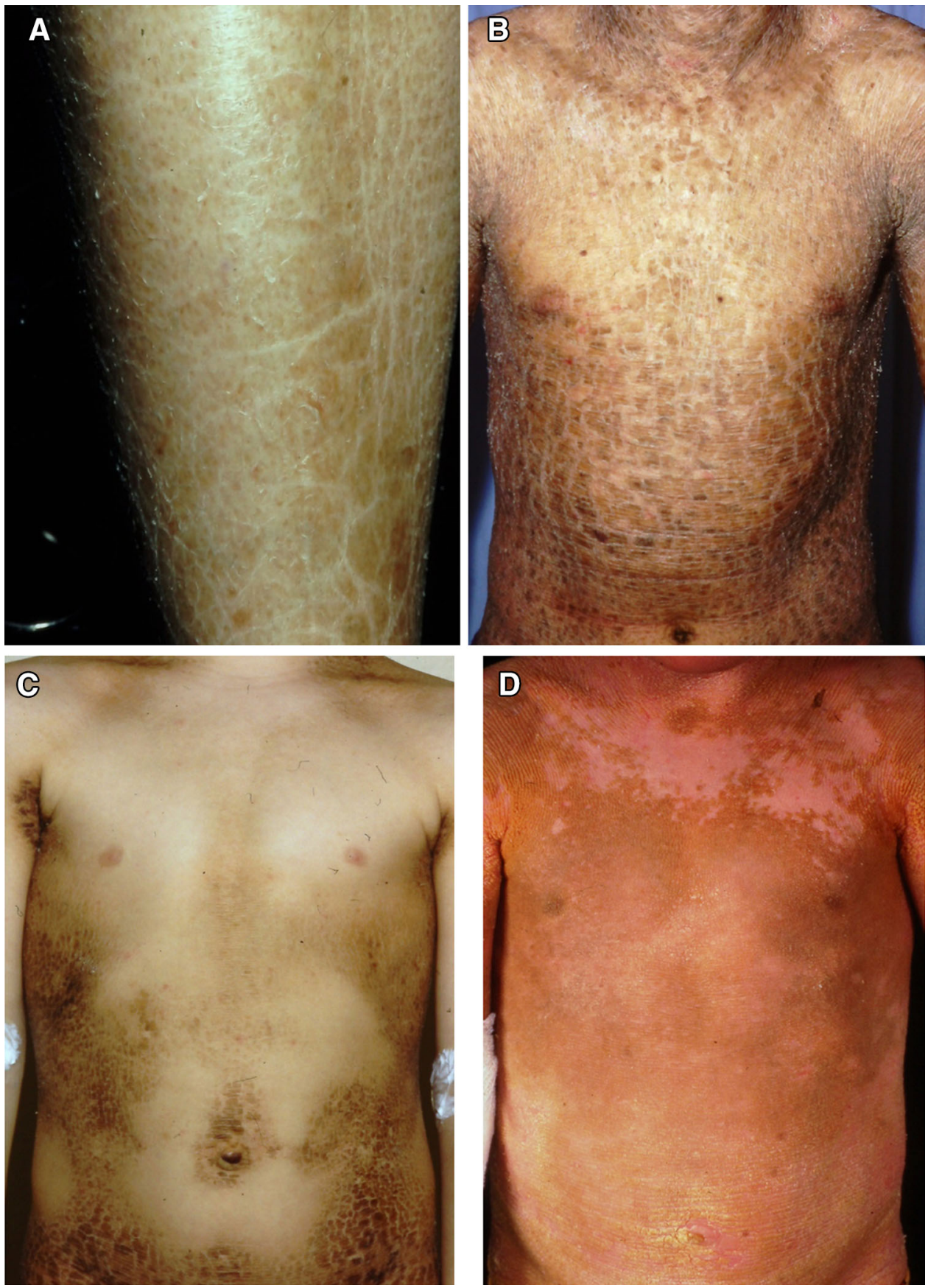
ARCI is a heterogeneous group of recessively inherited disorders with congenitally appearing ichthyosis but no extra-cutaneous involvement [3]. The most common mature phenotypes are generalized lamellar ichthyosis (LI) (Fig. 1b) and congenital ichthyosiform erythroderma (CIE), often combined with palmoplantar keratoderma, ectropion, and anhidrosis. However more severe as well as milder phenotypes also occur (Fig. 1c). Irrespective of the patients' mature phenotype, they are frequently born as collodion babies, and in the rare case of harlequin ichthyosis (HI) this is associated with an increased perinatal mortality.

Epidermolytic ichthyosis is the major variant of keratinopathic ichthyosis, an umbrella term for ichthyosis caused mostly by dominant-negative mutations in the keratin genes $K R T 1, K R T 2$, or KRT10 [3]. Epidermolytic ichthyosis is characterized by hyperkeratosis, erythroderma, and superficial skin fragility (Fig. 1d) with or without palmoplantar keratoderma. Newborns may show widespread blistering resembling epidermolysis bullosa. A rare non-blistering form, ichthyosis with confetti resembles CIE in infancy, but patients later develop progressive spots with healed skin.

Common for all types of ichthyosis is the life-long persistence of various skin problems and-in the severe types-high patient morbidity and distress also affecting the relatives and families [4].

\section{Pathophysiology}

Virtually all types of ichthyosis show abnormal properties of the two outermost skin layers, the stratum granulosum and the stratum corneum, causing impairments of the skin barrier function. However, there are important differences in the molecular defects of barrier impairment in different types of ichthyosis, as well as differences in the compensatory responses elicited by the skin, which to a large extent determines the patient's signs and symptoms [5, 6]. For a full discussion of these matters, a short description of the normal keratinization process is not out of place.

\subsection{Basic Features of Normal Keratinization}

Among the many functions of the skin, probably the most important is to act as a barrier against unlimited transepidermal water loss (TEWL) and exposure to various noxious environmental factors. The stratum corneum is the most essential component of the barrier, principally consisting of a cellular compartment (corneocytes) and an intercellular compartment (keratinocyte-derived lipids) bridged by numerous corneodesmosomes that undergo proteolytic degradation upon shedding of corneocytes (Fig. 2). This proteolytic process is a complex function involving several enzymes and anti-proteases [7].

During terminal differentiation of keratinocytes, abundant synthesis and modification of specific lipids and proteins occurs in the upper stratum spinosum, essential for proper barrier function and hydration of the stratum corneum. The various lipids are transported to the horny layer in several different ways. Whereas cholesterol sulphate may freely diffuse from the cytosol to the extracellular spaces [8], free fatty acids, cholesterol, and glycosylceramides (precursors of stratum corneum ceramides) are first packed into the lamellar bodies, together with a number of enzymes and antimicrobial peptides [9]. In the upper

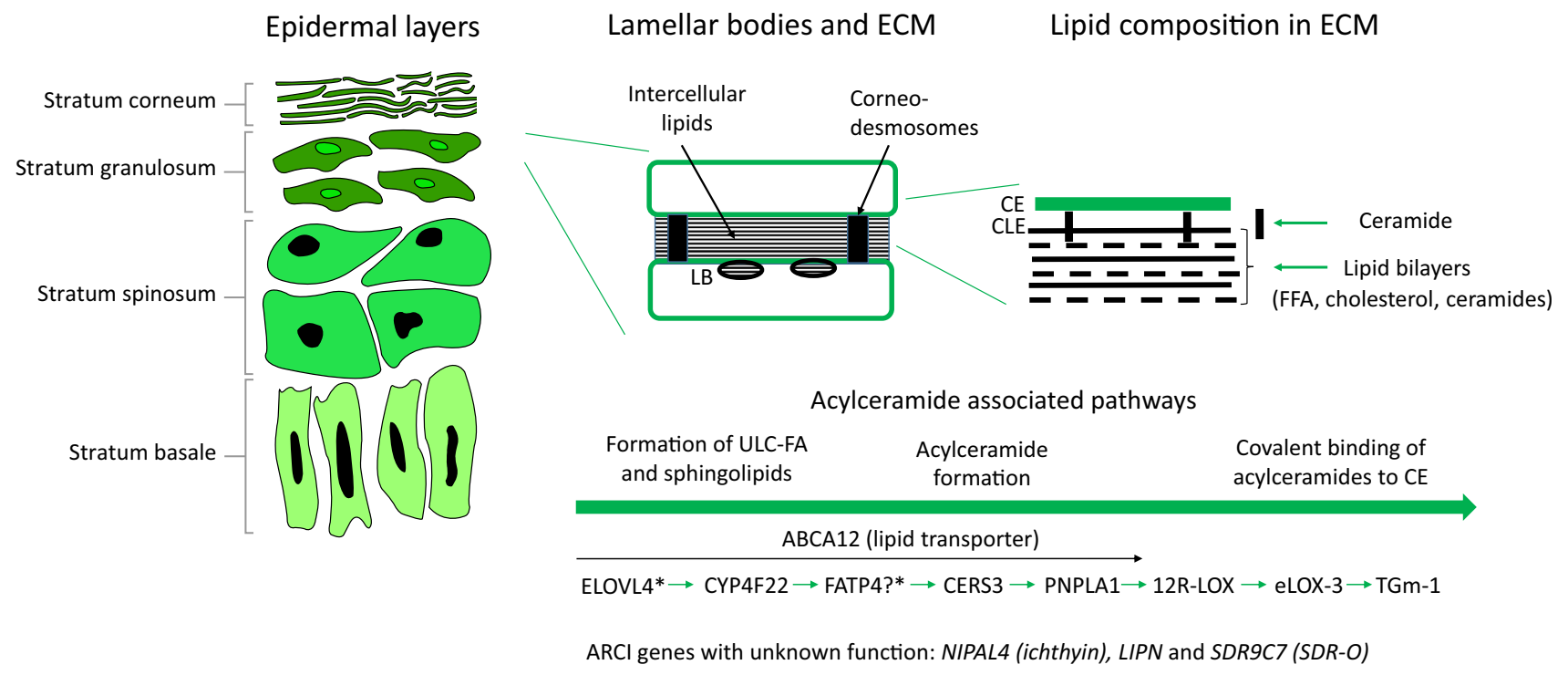

Fig. 2 Diagram of ARCI pathophysiology. For protein/enzyme abbreviations see Table 1. ARCI autosomal recessive congenital ichthyosis, CE cornified envelope, CLE corneocyte lipid envelope,
$E C M$ extracellular matrix, $F F A$ free fatty acids, $L B$ lamellar bodies, $U L C$-FA ultra-long-chain fatty acids. Asterisk indicates proteins defective in syndromic ichthyosis 
stratum granulosum, the lamellar bodies start to fuse with the plasma membrane and release their content to the intercellular space, forming a continuum of lipids organized as lamellar structures. Concurrently, keratohyaline granules, containing $400 \mathrm{kDa}$ profilaggrin, start to release $37 \mathrm{kDa}$ filaggrin monomers after cleavage by specific proteases. The filaggrin monomers bind to keratin, resulting in a compression of the cytoskeleton, and are further degraded to, for instance, urocanic acid and histidine, which provide UV protection and hydration (the natural moisturizing factor).

A crosslinking of keratinocyte-derived involucrin and loricrin also occurs during the transition of granular cells to corneocytes, resulting in a rigid cornified cell envelope (CE). The principal enzyme involved in this process is transglutaminase 1 (TGm-1). Suprabasal keratinocytes also synthesize new types of keratins (KRT1, KRT2, and KRT10) that form heterodimers that readily polymerize into intermediate filaments, essential for cellular stability and integrity.

Crucial to this whole discussion is the dramatic stress that the epidermis is exposed to at birth, reflecting a shift from a hydrated fetal environment to a postnatal dry environment. This stress will markedly impact the cornification process, especially in the case of a pathologic epidermis, such as in congenital ichthyosis.

\subsection{Common Versus Idiopathic Abnormalities in Ichthyosis}

In principle, hyperkeratosis is a combined or isolated result of three mechanisms: (1) epidermal hyperproliferation, (2) increased cohesion of corneocytes, and (3) decreased desquamation from the skin surface. Especially in the severe types of ichthyosis, all three of these mechanisms may be operative. Hyperproliferation can be considered as a homeostatic response that will continue as long as the underlying barrier defect persists [5]. An increased synthesis of epidermal lipids is also a very common response [5]. A noteworthy exception to this scheme of events is $\mathrm{X}$-linked ichthyosis due to deficiency of steroid sulphatase [10] leading to an accumulation of cholesterol sulphate that will inhibit the proteolysis of corneodesmosomes and hence impede desquamation [11]. This retention of corneocytes apparently compensates for many of the intrinsic defects in the lipid barrier, also explaining why the epidermal repair machinery appears quiescent in patients' affected skin as compared with patients with ichthyosis vulgaris of comparable severity, showing major alterations in gene activation associated with barrier repair [12-14].
In the severe forms of ichthyosis, such as ARCI and epidermolytic ichthyosis, erythema is another common feature. To some extent, this sign of dermal inflammation can be explained by the cytokines released from the epidermis in response to a major defect in the skin barrier, but exactly how it occurs is still unclear. In a recent report, the immune profiles in a group of ichthyosis patients were analyzed and correlated with clinical features and TEWL values [15]. Interestingly, patients with severe ARCI and epidermolytic ichthyosis showed immune profiles akin to psoriasis (induction of interleukin [IL]-17-related genes, etc.), except that tumor necrosis factor- $\alpha$ (TNF- $\alpha$ ) was normal [15].

\subsection{Other Pathological Consequences}

Importantly, the barrier defects in nonsyndromic ichthyosis may per se have systemic consequences. For example, enhanced penetration of allergens can help to explain atopic sensitization in ichthyosis vulgaris and, most likely, also in ichthyosis prematurity syndrome (IPS). Incidentally, 'syndrome' is probably a misnomer for the latter disease, because all its extra-cutaneous features, including prematurity and neonatal asphyxia, can be explained by intrinsic defects in epidermis causing massive accumulation of skin debris in the amniotic fluid from mid-gestational stages and onwards [16, 17]. IPS is therefore included among ARCIs in this and earlier publications $[16,17]$.

Other systemic consequences of severe, nonsyndromic ichthyosis, particularly in harlequin infants, are increased caloric and nutrient requirements. This owes to a combination of overheating due to anhidrosis, increased epidermal turnover, and dermal inflammation, altogether resulting in a risk of growth failure [18]. A further complication is increased susceptibility to bacterial infections, mainly due to skin fissures and erosions. However, in HI and epidermolytic ichthyosis, the increased susceptibility can also be explained by a deficient release of anti-microbial peptides (AMPs) by abnormal lamellar bodies $[19,20]$. On the other hand, epidermal AMPs were recently shown to be upregulated in ichthyosis due to TGm-1 deficiency [20], possibly explaining why cutaneous infection is not a major problem in all patients with ARCI.

For a more complete update on the pathophysiology of the various types of ichthyosis, the reader is referred to excellent reviews by Schmuth et al. [21, 22], Marukian and Choate [22], and McLean [23].

For an overview of the mutated genes implicated in the etiology of non-syndromic ichthyosis, see Table 1. 
Table 1 Summary of the etiopathogenetic mechanisms in three distinct subtypes of nonsyndromic ichthyosis

\begin{tabular}{|c|c|c|c|c|c|}
\hline Defective function & Culprit protein/enzyme & Gene & Locus & Inheritance & $\begin{array}{l}\text { Relative } \\
\text { frequency } \\
(\%)^{\mathrm{a}}\end{array}$ \\
\hline \multicolumn{6}{|c|}{ Ichthyosis vulgaris (IV) and pathogenetically related ichthyosis } \\
\hline \multirow{2}{*}{$\begin{array}{l}\text { IF consolidation and SC hydration mediated } \\
\text { by filaggrin (FLG) }\end{array}$} & Pro-filaggrin (Pro-FLG) & $F L G$ & $(1 \mathrm{q} 21.3)$ & ASD & 100 \\
\hline & Caspase-14 (FLG release) & CASP14 & $(19 \mathrm{p} 13.12)$ & $\mathrm{AR}$ & ND \\
\hline \multicolumn{6}{|c|}{ Autosomal recessive congenital ichthyosis (ARCI) } \\
\hline CE cross-linking and lipid attachment & Transglutaminase-1 (TGm-1) & $T G M 1$ & $(14 q 11.2)$ & $\mathrm{AR}$ & $32-42$ \\
\hline \multirow{9}{*}{$\begin{array}{l}\text { Ceramide bio-synthesis and generation of } \\
\text { intercellular lipid bilayers }\end{array}$} & 12R-lipoxygenase (12R-LOX) & $A L O X 12 B$ & $(17 \mathrm{p} 13.1)$ & $\mathrm{AR}$ & $7-12$ \\
\hline & Epidermal lipoxygenase-3 (eLOX-3) & ALOXE3 & $(17 \mathrm{p} 13.1)$ & $\mathrm{AR}$ & $5-7$ \\
\hline & $\begin{array}{l}\text { ATP-binding cassette sub-family A member } \\
12 \text { (ABCA12) }\end{array}$ & $A B C A 12$ & $(2 \mathrm{q} 34)$ & $\mathrm{AR}$ & $5-6$ \\
\hline & Cytochrome P450 4F22 (CYP4F22) & $C Y P 4 F 22$ & $(19 \mathrm{p} 13.12)$ & $\mathrm{AR}$ & $2-8$ \\
\hline & $\begin{array}{l}\text { Magnesium transporter NIPA4 (NIPAL4, } \\
\text { ichthyin) }\end{array}$ & NIPALA & $(5 \mathrm{q} 33.3)$ & $\mathrm{AR}$ & $11-16$ \\
\hline & $\begin{array}{l}\text { Short-chain dehydrogenase/reductase family } \\
\text { 9C member } 7 \text { (SDR-O) }\end{array}$ & SDR9C7 & $(12 q 13.3)$ & $\mathrm{AR}$ & $2-4$ \\
\hline & Ceramide synthase-3 (CERS-3) & CERS3 & $(15 q 26.3)$ & $\mathrm{AR}$ & $<1$ \\
\hline & $\begin{array}{l}\text { Patatin-like phospholipase domain- } \\
\text { containing protein } 1 \text { (PNPLA1) }\end{array}$ & PNPLA1 & $(6 \mathrm{p} 21.31)$ & $\mathrm{AR}$ & $1-3$ \\
\hline & $\begin{array}{l}\text { Long-chain fatty acid transport protein } 4 \\
\text { (FATP4) }\end{array}$ & SLC27A4 & $(9 \mathrm{q} 34.11)$ & $\mathrm{AR}$ & $<4^{\mathrm{b}}$ \\
\hline \multicolumn{6}{|l|}{ Keratinopathic ichthyosis (KPI) } \\
\hline \multirow[t]{3}{*}{ Suprabasal IF assembly } & Keratin $1(\mathrm{~K} 1)$ & $K R T 1$ & $\begin{array}{l}(12 \mathrm{q} 12- \\
\mathrm{q} 13)\end{array}$ & $\mathrm{AD}$ & $22-45$ \\
\hline & Keratin 10 (K10) & KRT10 & $(17 \mathrm{q} 21)$ & $\mathrm{AD}(\mathrm{AR})$ & $54-60$ \\
\hline & Keratin 2 (K2) & $K R T 2$ & $\begin{array}{l}(12 \mathrm{q} 11- \\
\mathrm{q} 13)\end{array}$ & $\mathrm{AD}$ & $1-14$ \\
\hline
\end{tabular}

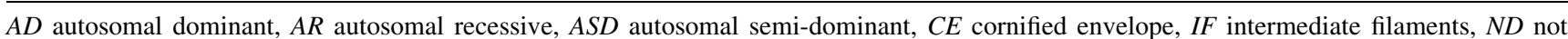
determined, $S C$ stratum corneum

${ }^{a}$ European figures compiled from comparatively large study cohorts of patients with IV [23], ARCI (and $>7$ of the candidate genes analyzed) $[17,97,98]$ and unpublished data, or KPI $[77,79,120]$

b An even higher figure is noted in Norway due to a genetic founder effect for ichthyosis prematurity 'syndrome' [16]

\subsection{Ichthyosis Vulgaris}

Patients with this type of ichthyosis (OMIM 146700) exhibit a moderately defective skin barrier reflected in slightly increased TEWL [24] and frequent occurrence of atopic manifestations [23]. It has long been recognized that the patients' differentiated keratinocytes either lack or have markedly reduced levels of keratohyaline granules. In 2006 this was shown to be due to loss-of-function mutations in the filaggrin $(F L G)$ gene, located on chromosome 1q21, known to contain the epidermal differentiation complex [25-27]. The mutations result in truncated profilaggrin proteins that cannot be processed to filaggrin and its further breakdown products, thus leading to a dry, disorganized horny layer with poor barrier properties. The most common mutations in European populations are R501X and 2282del4, whereas Asian populations show a more diversified mutation panorama. Interestingly, mutations in FLG are quite common in the general population, especially in populations of White Caucasian ancestry with prevalence figures of 2.7-9\% [28]. Both TEWL and the number of differentially expressed genes in the epidermis (reflecting the compensatory barrier repair) increase in relation to the impact of $F L G$ mutations, being higher in patients with homozygous mutations than in those with heterozygous mutations [13].

Recently, Kirchmeier et al. described three patients with a very mild ichthyosis due to biallelic mutations in the gene CASP14 [29]. The gene product, caspase 14, is involved in the proteolytic degradation of filaggrin [30]. The patients were born without a collodion membrane and developed a skin phenotype with fine whitish scales over the whole body without erythema or other skin symptoms. The skin phenotype of patients with CASP14 mutations thus seems to correspond to a clinical grey zone between ichthyosis vulgaris and mild type ARCI. 


\subsection{Autosomal Recessive Congenital Ichthyosis (ARCI)}

ARCI is a genetically and phenotypically heterogeneous group of disorders that includes HI, LI, and CIE [3]. A fourth group of patients with milder phenotypes has previously been described as 'non-LI/non-CIE'. Recently, a new name, pleomorphic ichthyosis (PI), was proposed for this subgroup [31], based on one of the definitions of pleomorphism: "a condition in which an individual assumes a number of different forms during its life cycle" (Oxford Medical Dictionary). At birth, patients in the PI subgroup usually show severe signs of ichthyosis, but following a spontaneous improvement during childhood, only minor skin symptoms remain thereafter, albeit sometimes exaggerated by environmental factors, such as heat and skin irritation [17, 31]. Examples of disorders fitting into this group are IPS (see Sect. 2.3), self-healing collodion baby/self-improving collodion ichthyosis, and bathing suit ichthyosis (see Fig. 1c; for review see [31]) (also see footnote). ${ }^{1}$

ARCI is caused by mutations in more than a dozen different genes, including TGM1 [33], ABCA12 [34], CYP4F22 [35], ALOXE3/ALOX12B [36], NIPAL4 [37], CERS3 [38-40], SDR9C7 [41], PNPLA1 [42-44], SLC27A4 [45], and LIPN [46], a very rare cause of noncongenital ichthyosis not discussed in this context. Also relevant for a discussion of ARCI pathogenesis is ELOVL4 [47], a gene which is associated with syndromic ichthyosis, but nonetheless operates with the ARCI genes in a metabolic pathway essential for the production of a specific acylceramide moiety, $\omega$-hydroxy-acylceramide $(\omega$-HAC), eventually bound to the CE (see Fig. 2).

Support for this concept comes from results obtained in knock-out mice and from studies of patients with mutations in several of the genes causing ichthyosis (e.g., $A B C A 12$ [32], CERS3 [38-40], ELOVL4 [48, 49], CYP4F22 [50], PNPLA1 [51], ALOXE3 [52], ALOX12B [52]), all showing either defective lamellar bodies or aberrant lipid synthesis resulting in an altered content of long-chain acylceramides in the epidermis. This strongly suggests that the formation of the $\omega-\mathrm{HAC}$ and its covalent binding to the CE are crucial for the inside-out barrier function of the skin. Another example of the importance of ARCI-related proteins for the acylceramide pathway comes from the observed reduction of TGm-1 expression after a single UVB exposure in mice and a concomitant downregulation of covalently bound acylceramides in the skin [53].

\footnotetext{
1 While already used by several authors, the umbrella term pleomorphic ichthyosis was not proposed until after the Terminology Consensus Meeting in Sorèze 2009 [32], and hence no consensus exists about its use.
}

The list of ARCI genes in Table 1 is complemented here by a more detailed account of each gene in no specific order.

$A B C A 12$ In a mouse model lacking $A B C A 12$ expression, a profound reduction in the skin level of linoleic esters of $\omega$-HACs has been reported [32], and by using this animal model, a defect in the lipid transfer to the intercellular space was found together with a lack of proteolytic enzymes (kallikreins) required for desquamation of corneocytes [54]. Thus, although lamellar bodies are usually regarded as mainly important for intracellular storage and transportation of lipids, they also contain a number of proteins which are of importance for other functions related to the skin barrier. Importantly, non-truncating mutations in $A B C A 12$ can cause a much milder phenotype than $\mathrm{HI}$ (i.e., more similar to LI/CIE) [34].

CERS3 Mutations in CERS3 impair ceramide biosynthesis and are causative for ARCI [38, 39]. In terminally differentiating patient keratinocytes, a loss of ceramides with very long acyl chains from C26 up to C34 was found $[38,39]$. Similar results were also observed in a CERS3deficient mouse model $[39,40]$.

CYP4F22 This cytochrome P450 enzyme is also crucial for the formation of acylceramides, and its role together with other enzymes (i.e., ELOVL4 and CERS3) was recently elucidated [50]. CYP4F22 was convincingly shown to be an epidermal $\omega$-hydroxylase, preferentially hydroxylating ultra-long-chain fatty acids (ULCFA). The data is corroborated by another recent paper describing defects in epidermal maturation and barrier function in ARCI patients with CYP4F22 mutations [55]. At the ultrastructural level, the authors found fragmented and disorganized lamellar lipid bilayers, as well as lamellar bodies and lipid entombment in the corneocytes [55]. Although the former organelles appeared smaller, their density was increased, suggesting a compensatory mechanism. The abnormal lamellar bilayers were therefore speculatively ascribed to inhomogeneous and premature secretion of lamellar bodies.

SLC27A4 Interestingly, Ohno et al. [50] recently proposed a role in the acylceramide pathway also for the IPS-causing protein FATP4, suggested to act as an acyl-CoA synthase rather than a fatty acid transporting protein in keratinocytes. This proposal was concurrently established in SLC27A4 knock-out mice [56], additionally showing that the animals' defective skin barrier could be rescued by inducing wild-type expression of FATP1 in the suprabasal keratinocytes. In normal mice, FATP1 expression predominates over FATP4 in adult epidermis, whereas FATP4 predominates in fetal epidermis [57]. If these findings can be extrapolated to the human situation, it becomes possible to explain why the severe phenotype in neonates with IPS (lacking FATP4) gradually changes into a mild phenotype ('rescued' by FATP1) [58]. 
PNPLAl The enzyme produced by this gene has also been shown to play a role in the acylceramide pathway. Recent studies show that PNPLA1-deficient mice and patients' keratinocytes lack unbound and CE-bound $\omega$ HACs $[51,59]$. This proves that PNPLA1 is involved in the synthesis of $\omega$-HACs, acting as an acyltransferase involved in the addition of linoleic acid to $\omega$-hydroxy-ULCFA [59]. Furthermore, PNPLA1 was shown to catalyze acylceramide synthesis with triglyceride as a substrate in vitro and this activity was reduced or abolished using mutant forms of PNPLA1 found in patients with ichthyosis [60].

ALOXE3/ALOX12B The lipoxygenases, eLOX-3 and 12R-LOX, participate in the removal of linoleic acid from $\omega$-HAC, thereby generating $\omega$-hydroxy-ceramide for subsequent covalent binding to the lipid envelope $[52,61]$. In addition, an involvement in the processing of this lipid has been demonstrated [62, 63]. Mutations in ALOXE3/ $A L O X 12 B$ are frequently associated with mild types of ARCI, such as self-improving collodion ichthyosis [64].

TGM1 Mutations in this gene are the predominant cause of ARCI, especially of the LI subtype. The enzyme, TGm1 , was initially reported to cross-link soluble cytoplasmic proteins onto the plasma membrane to form the CE [65, 66] to which $\omega$-hydroxy-ceramide is then covalently bound, a process that was later reported to also involve TGm-1 [67]. However, a more recent report shows that ARCI patients with absent or low TGm-1 activity may still exhibit normal levels of protein-bound ceramides [68]. This exemplifies the complexity of the pathway generating protein-bound ceramides and is a stimulus for further studies of how exactly $\omega$-hydroxy-ceramides are covalently bound to the CE.

NIPAL4 Although mutations in this gene (initially named Ichthyin) are undoubted causes of ichthyosis in humans [37, 69] and in dogs [70], the function(s) of the protein remains enigmatic [58, 71, 72]. It has been suggested to be $\mathrm{Mg}^{2+}$ transporter and this cation might act as a co-factor for the synthesis of very long chain fatty acids by FATP4 (note that the latter also might function as a fatty acid transporter) [73]. An interaction between NIPAL4 and FATP4 has been observed in normal human skin [58]. Ultrastructural analysis of epidermis from patients with NIPAL4 mutations shows abnormal lamellar bodies and perinuclear elongated membranes in the granular layer [69], possibly indicating a role of NIPAL4 in lipid processing (or representing cytotoxic effects from accumulating metabolites).

SDR9C7 This is the most recently identified ARCI gene, encoding a protein belonging to the family of short-chain dehydrogenase/reductases [41, 74]. These enzymes are known to catalyze the metabolism of various ligands for nuclear receptors, such as prostaglandins, retinoids, and several classes of steroid hormones. However, SDR9C7 shows only low activity for converting all-trans retinal into all-trans retinol and no activity for various steroid substrates [75], making other lipids more likely as substrates for this enzyme. A recent study showed deficient intercellular lipid and malformation of intercellular lipid layers in a patient with a novel mutation in SDR9C7 [74].

\subsection{Keratinopathic Ichthyoses}

This group of skin disorders is caused by mutations in keratins expressed by suprabasal keratinocytes [76-79]. Epidermolytic ichthyosis is caused by heterozygous mutations in the KRT1 and KRTIO genes, superficial epidermolytic ichthyosis by mutations in KRT2 causing a mild phenotype, and Ichthyosis variegate (ichthyosis with confetti/congenital reticular ichthyosiform erythroderma) by a particular type of mutation in KRT10 and KRT1 which initially causes ichthyosiform erythroderma that later in life shows signs of spontaneous revertant mosaicism [76, 78]. Curth-Macklin is yet another type of rare keratinopathic ichthyosis, ultrastructurally characterized by binucleated keratinocytes [76]. In addition, there are mosaic (nevoid) forms of epidermolytic ichthyosis that will not be discussed here, but may be of significance in the context of genetic counseling.

The disease-causing keratin mutations often occur in certain hotspot regions, changing the protein structure so that its hetero-dimerization is altered, thus resulting in cytoskeletal fragility. This can be nicely visualized by electron microscopy (EM) analysis of patients' epidermis [80], or experimentally by exposing patient cultured cells to osmotic or heat stress, which causes aggregation of the keratin filaments [81].

In addition to causing epidermolysis, the keratin mutations may perturb the skin barrier function by interfering with the secretion of lamellar bodies and affecting the extracellular lipid membrane formation [82], thus seemingly converging with some aspects of the ARCI pathogenesis.

\section{Diagnosis}

\subsection{Clinical Signs and Symptoms}

Given the conspicuous signs of widespread hyperkeratosis, scaling, xerosis, erythema, and occasional skin erosions, one may think that it is always easy to make a clinical diagnosis of ichthyosis and that patients seeking a doctor are likely to receive correct information about the disease and its treatment. In reality, however, the severe forms of ARCI and keratinopathic ichthyosis may easily be misdiagnosed as syndromic ichthyosis or epidermolysis bullosa (in neonates), and the milder forms as ichthyosis vulgaris 


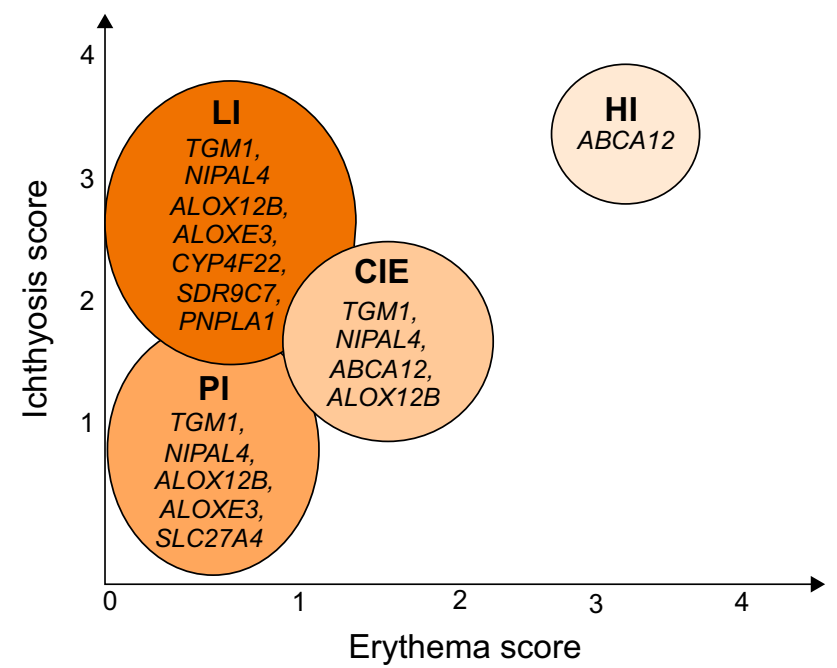

Fig. 3 The relationship between ichthyosis and erythema severity post-infancy in the four subtypes of autosomal recessive congenital ichthyosis (ARCI): Lamellar ichthyosis (LI), congenital ichthyosiform erythroderma (CIE), pleomorphic ichthyosis (PI), and harlequin ichthyosis (HI). The ARCI genes most commonly mutated are indicated for each subgroup in order of the frequency observed in a Scandinavian cohort [17]. The position, shape, and size of the circles (or ellipses) reflect the mean score ranges and relative number of patients (from [17]). Except in the case of HI with truncating $A B C A 12$ mutations, some overlapping does occur, both clinically and genetically, between the other groups. (Modified from [17] by permission from the publisher)

(in older children and adults) or X-linked ichthyosis (in males), and vice versa. These and other diagnostic challenges encountered when trying to distinguish one type of ichthyosis from another and excluding syndromic disorders have recently been reviewed [83].

Traditionally, the type of scaling (fine, coarse, lamellar, etc.) and severity/extension of ichthyosis and erythema, together with the patient's own and family history, form the basis of a first subgrouping of ichthyoses. If ARCI is suspected, further clinical subtyping may be facilitated by looking at the relationship between ichthyosis and erythema severity in the four main types of ARCI, also providing a hint about the most likely candidate genes (Fig. 3). The severity of ichthyosis and erythema is usually graded from mild to very severe (0-4). Although more elaborate scoring systems for the evaluation of skin xerosis, palmoplantar keratoderma, and disease extension have been proposed [84-87], none of these protocols has been properly validated and no consensus exists about which one is the best to use in clinical practice and clinical trials.

Nonetheless, careful skin examination is essential, because even a singular finding may actually help to predict the patient's genotype (see the following four examples).

1. Although palmoplantar keratoderma is common in most types of ARCI, when seen in a patient with epidermolytic ichthyosis it almost invariably reflects an underlying KRT1 mutation [88].

2. When a child previously diagnosed with erythrodermic ARCI ('cause unknown') starts to develop characteristic spots of healed skin, a diagnosis of ichthyosis variegate becomes obvious [89].

3. Infants with $\mathrm{HI}$ almost invariably have $A B C A 12$ mutations, and the most severely affected patients born with a collodion membrane frequently have TGM1 mutations (see Sect. 2.5).

4. More than 6 weeks of prematurity, combined with massive hyperkeratosis on scalp and face as in IPS, prompts a search for SLC27A4 mutations [45].

\subsection{Microscopy and Ultrastructural Analysis}

Routine skin histology is seldom of foremost value in the diagnosis of ichthyosis, except in ichthyosis vulgaris where an absence of the granular layer is suggestive, and in some forms of keratinopathic ichthyosis where epidermolysis occurs in the upper epidermis. Immunohistochemistry (IHC) can be of help in the diagnosis of ichthyosis vulgaris and ARCI, provided antibodies are available against the suspected candidate protein and the patient's mutation(s) causes a deletion or distinctly abnormal protein expression in the epidermis. IHC is less useful in the keratinopathic disorders, but has been described as a diagnostic test for ichthyosis variegate [90]. It can also be used to exclude certain differential diagnoses, such as Netherton syndrome (negative for LEKTI staining in the upper epidermis).

EM was in the past instrumental for deciphering various types of ichthyosis, and several pathognomonic EM patterns in the upper epidermis were described in association with ARCI and keratinopathic ichthyosis [80]. The problem with EM, however, is that it is costly, time consuming, and requires special pathological expertise not widely available. EM analysis is, however, very useful in characterizing the CE, cell organelles in granular cells, and aberrant lipid structures in the epidermis using ruthenium tetroxide post-fixation, which nicely visualizes the lipid envelopes and lipid bilayers in the stratum corneum [91-95]. New and rare causes of ichthyosis, and various differential diagnoses such as acantholytic disorders caused by $D S G 1$ mutations, may also benefit from EM analysis, especially when no causative mutations have been found (for examples see $[69,85,96]$ ).

\subsection{Genetic Testing}

For more than 30 years the gold standard for genetic analysis was the dideoxy sequencing (Sanger sequencing 
method; first generation) by which the coding part of the suspected disease-causing gene was analyzed, exon by exon. This was an expensive and time-consuming approach compared with the now available next generation (NGS) techniques. Since the early 2000 s, technologies of massive parallel sequencing have been developed and applied for large-scale genetic diagnostics, especially in genetically heterogeneous diseases. Using NGS it has become possible to analyze the complete coding portion of a genome or even the whole genome in a few days. Several companies have developed 'second-generation sequencing' which is still based on a PCR amplification step also called 'enrichment'. Other less error-prone techniques, based on single molecule amplifications, will be available in the near future.

There are ichthyosis phenotypes with obvious clinical diagnosis in which the clinician can clearly assign a particular gene (see Sect. 3.1). But the remaining patients, especially those with mutations in ARCI genes, cannot be clearly distinguished from each other, even by very experienced clinicians. Therefore, the NGS methods such as multi-gene-panel sequencing that include all suspected candidate genes within one analysis are a perfect diagnostic approach.

However, this method cannot replace the detailed anamnestic and clinical investigations. There are different rules and approaches in different countries. In practice, the common step is the analysis of a multi-gene panel covering a well-defined group of clinically compatible diseases with a limited number of genes. If no mutations can be identified, an extended number of genes will be analyzed or a clinical exome with analysis of 3000-5000 genes or a whole exome sequencing will be performed.

Exome sequencing produces a large amount of data including sequence variants that cannot be clearly interpreted as disease-causing or nonpathogenic. Furthermore, large-scale sequencing may lead to additional and coincidental findings. Nevertheless, by an extensive screening of ichthyosis-related mutations, virtually all investigated patients with nonsyndromic ichthyosis can be molecularly diagnosed [97, 98]. For example, in a more recent study of 132 patients with ARCI we found causative mutations in $85 \%$ of cases [16, 17], and five of the remaining 19 patients have since been diagnosed with mutations in the newly discovered gene, $S D R 9 C 7$, increasing the number of successful screenings to almost $90 \%$ (JF et al., to be published). To reach $100 \%$, several new ARCI genes probably have to be identified.

When novel mutations are found, it is sometimes hard to predict their disease-causing potential. For instance, a trivial point mutation in TGMI may change the 3D structure of TGm-1 but only at elevated skin temperature, thus explaining a variably reduced enzyme activity in bathing suit ichthyosis [99] (see also Fig. 1c). A further complexity of the genotype/phenotype correlation arises in ARCI patients who have compound heterozygous mutations, or carry additional genetic traits for more common skin disorders, such as ichthyosis vulgaris and poly-genetically inherited psoriasis vulgaris [100].

\section{Treatment-What's New?}

A systematic review of clinical trials of various treatments for congenital ichthyosis has recently been published [101]. Adding to previous reviews [102, 103], an updated overview of common and more unorthodox and innovative therapies is given below.

\subsection{Emollients and Other Topical Treatments}

Symptomatic treatment with emollients and topical keratolytics remains the mainstay therapy for ichthyosis, and should be maintained also when adjuvant systemic agents are prescribed. Intuitively, one may think that a therapeutic removal of hyperkeratosis-the intrinsic response to increased TEWL in ichthyosis [104]—might further exaggerate the barrier defect and thus enhance the pathophysiology of the disease. However, in real life this appears to be a minor problem as long as the TEWL values remain within reasonable limits and the risk of increased transcutaneous penetration of topically applied agents is taken into consideration [101].

Individualized therapy, taking into account the type and severity of ichthyosis and the patient's own preferences, is essential for the successful outcome of all topical treatments. Glycerol, urea, and propylene glycol are the most commonly used hydrating ingredients, usually in cream formulations [1, 87, 103]. By mixing hydrating and keratolytic agents in the right combinations, surprisingly effective creams can be obtained [87, 104, 105]. However, the risk of systemic absorption of the ingredient, especially in infants treated over the whole body, must always be considered. This is not just the case for salicylic acid, but also for $\alpha$-hydroxy acids, such as lactic acid, which if used too frequently and in high concentrations may produce severe and even lethal intoxications [106].

In severe cases or when monotherapy with emollients has proven insufficient, more specific topical 'anti-keratinizing' agents should be added. One such compound is $\mathrm{N}$ acetylcysteine, which together with urea yielded good results in a small study of children with LI [107]. The odor from sulfur appears to be minimized by an improved formula [108]. Tazarotene is an aromatic retinoid initially approved for the treatment of psoriasis, but also shown to be effective in ichthyosis, albeit sometimes irritating (see 
[103] and references therein). When applied carefully on the eye lids of children with ectropion, some good results have been reported [109]. However, when used on large body areas the risk of systemic absorption must be weighed against the benefits [110], and the costs of daily applications will be high.

Topical vitamin D derivatives, such as calcipotriol originally developed for psoriasis, have been successfully tested in a limited number of patients with ARCI and epidermolytic ichthyosis [111-113]. To reduce the risk of systemic vitamin D toxicity from transcutaneous penetration of the drug, the manufacturer recommends a dose limitation of $5 \mathrm{mg}$ per week in adults (corresponding to $100 \mathrm{~g}$ of cream), which probably obviates daily applications on large body areas.

\subsection{Systemic Agents}

\subsubsection{Retinoids}

Over the years, many types of systemic therapies have been tested in ichthyosis. However, oral acitretin and to a lesser extent isotretinoin remain the most popular drugs. Related drugs, such as alitretinoin [114] and retinoid acid metabolism-blocking agents (RAMBAs) [86], have been tested only on a limited scale. They are presently not generally approved therapies for ichthyosis and will therefore not be discussed further here.

The mechanism of action of retinoids in ichthyosis is mainly symptomatic, exerting rather unspecific 'anti-keratinizing' effects on hyperkeratotic skin (for review see [115] and [116]). Importantly, the drugs also cause adverse effects, including teratogenesis. Retinoids bind to nuclear transcription factors, which assist in regulating numerous genes and hence modulate epidermal proliferation and differentiation, as well as inflammation [117].

Because of their ability to modulate keratin expression, retinoids may specifically influence the pathogenic process in keratinopathic ichthyosis. Keeping in mind the complex interactions and redundancies between type I and type II keratins expressed in the upper epidermis, a marked downregulation of KRT2 and up-regulation of KRT4 and 10 by retinoids [118, 119] can help to explain why the treatment response in epidermolytic ichthyosis apparently depends on the patient's genotype: a KRT2 mutation predicts a good response, a KRT10 mutation predicts an intermediate response, and a KRT1 mutation predicts a poor response (or even a worsening, presumably due to a lack of KRT2 as a replacement for KRT1 in its dimerization with KRT10) [120].

Although acitretin is usually more efficacious than isotretinoin in the treatment of ichthyosis, there are situations in which the latter drug is preferable, mainly because of its more rapid elimination after stopping therapy and a slightly different side-effect profile compared with acitretin. This is a special concern in children (skeletal growth) and women of child-bearing ages (teratogenicity). By selecting the 'best' retinoid, applying 'retinoid holidays' during longterm treatment, tapering the dose as low as possible (while retaining efficient topical remedy), and close monitoring of the patient, the problems associated with retinoid therapy can be minimized (for review see [116]).

\subsubsection{Vitamin D and its Analogs}

As early as 1988, oral vitamin D3 was tried in the treatment of ichthyosis [121]. In a more recent study from India, seven 1- to 8-year-old children with ARCI or EI and diagnosed with rickets $(25-\mathrm{OH}$-vitamin $\mathrm{D}<4 \mathrm{ng} / \mathrm{mL})$ were given 60,000 IU of cholecalciferol for 10 days, followed by 400-600 IU daily as supplementation together with oral calcium [122]. Besides curing the rickets, all children were markedly improved in the skin within 1-3 months after starting therapy. Whether the effects of high doses of vitamin $\mathrm{D}$ on ichthyosis were due to a direct effect on keratinocytes (expressing vitamin D receptors) or were part of a general improvement in health is hard to tell. Anyway, one should always keep in mind that both children and adults with severe ichthyosis are prone to develop vitamin D deficiency, especially if they are dark skinned and live in geographic or cultural regions of the world with little sun exposure [113, 123]. Anecdotally, in a recent case report, oral retinoid therapy was blamed for precipitating vitamin D deficiency in children with ichthyosis [124].

\subsubsection{Anti-Inflammatory Drugs}

Despite erythema being a frequent symptom in many forms of ichthyosis, skin inflammation per se is hardly ever addressed by existing therapies. For obvious reasons, topical or systemic corticosteroids are usually contraindicated; the risk of adverse effects during long-term therapy is simply too great. The same goes for calcineurin inhibitors. Anecdotally, a case report of methotrexate therapy in erythrodermic ARCI was published in the late 1960s [125] and oral liarozole has been shown recently to suppress the dermal expression of IL-1 and TNF- $\alpha$ in LI patients [117], but otherwise anti-inflammatory treatment has hardly ever been addressed in the context of systemic ichthyosis therapy.

Against this background it is of great interest that Paller et al. [15], looking at the immune profiles of 21 genotyped patients with severe ichthyosis, found an IL-17-dominant profile suggesting that already available biological therapies for psoriasis might also be effective in ichthyosis. Furthermore, in an in vitro model of TGm1-deficient skin, 
O'Shaughnessy et al. [126] recently showed that treatment with an IL-1 antagonist reversed the LI phenotype, and Cottle et al. [127] have since found that fetal inhibition of inflammation in an Abcal2-/- mouse model could improve the harlequin phenotype. It will indeed be interesting to see if specific anti-inflammatory drugs and biologics may in the future become a treatment option in selected cases of severe ichthyosis.

\subsubsection{Enzyme Replacement and Substitution Therapies}

Recent experimental studies hold great promise in the field of enzyme replacement therapy (ERT) for ichthyosis. To this end, Aufenvenne et al. [128] prepared sterically stabilized liposomes with encapsulated recombinant human TGm-1 (rhTG1) and equipped with a cationic lipopeptide vector to mediate cellular uptake. Using a skin-humanized mouse model, it was shown that after 2 weeks of topical applications with the rhTG1 liposomes, the ichthyosis phenotype was normalized, including a restoration of the skin barrier function. No adverse effects were noted in this animal model. In another study [129], topical rhTG1 was used successfully on SCID mice to restore the TGm-1 activity and architecture of skin grafts from patients with truncating TGM1 mutations. Clinical trials are now planned, which — if proven successful_-would mean a big leap forward in the treatment of ichthyosis. Another example of a possible future ERT originates from experiments in ABCA12-deficient skin showing reduced desquamation due to a lack of kallikreins (see Sect. 2.5). Topical application of recombinant kallikrein apparently restored the proteolytic degradation of corneodesmosomes and partially normalized the skin phenotype [129]. However, ERT is unlikely to become a common remedy for all forms of ARCI, because the costs for developing ERT for each new enzyme is huge and etiologies other than TGM1 mutations are rare.

An interesting alternative to ERT, however, is to supplement the patient's skin with the missing ceramide metabolite, common to many forms of ARCI. In a recent paper, Grond et al. tested topical application of $\omega$-HAC on experimental animals lacking PNPLA1 (see Sect. 2.5) and observed a normalization of TEWL [51]. If substantiated by future studies on ARCI of different etiologies and by clinical trials, this approach could become a therapeutic breakthrough in ARCI.

\subsubsection{Cutaneous Gene Therapy}

Conceptually, perhaps the most attractive way to treat congenital ichthyosis would be to replenish the skin with a wild-type copy of the missing or dysfunctional gene (in ARCI), or to use antisense, RNAi, or gene editing technologies to silence dominant negative mutations (in keratinopathic ichthyosis). Accordingly, optimism was great around the turn of the millennium about future prospects for gene therapy of severe genodermatoses (for review see [130]). Alas, because of serious backlashes in other fields of human gene therapy, a moratorium was soon imposed. New and more realistic plans for cutaneous gene therapy have, however, been recently presented [131], although ichthyosis is not a primary focus and most ideas still remain to be realized and implemented.

\subsection{Other Therapeutic Aspects}

The management of severe ARCI and epidermolytic ichthyosis is a complex task often necessitating multidisciplinary teamwork, especially when it comes to treatment of infants, as described in detail elsewhere [132].

Skin problems of great concern, but sometimes overlooked by healthcare providers, are anhidrosis, ectropion, palmoplantar keratoderma, and scalp and ear canal involvement. Alas, current therapies for these symptoms are often suboptimal and new ideas are desperately needed. Anhidrosis, probably resulting from a plugging of the sweat ducts by hyperkeratosis, is sometimes improved by retinoid therapy [133]. But many patients remain hypohidrotic despite vigorous treatment ( $\mathrm{AV}$, personal observation), suggesting the existence of additional functional defects of the sweat glands. Importantly, anhidrosis is common also among the mildest forms of ARCI (PI) [17]. Besides the importance of sweat for controlling body temperature, a recent study indicates that sweat may also influence the local milieu in ichthyotic epidermis, as demonstrated by a further reduction of the TGm-1 activity in a case of bathing suit ichthyosis [134].

Ectropion, when resistant to oral or topical retinoid therapy, is often treated with skin transplantations, a procedure which typically has to be repeated at intervals of several years. In this context, a new and much simpler surgical approach using inverted suturing of the eyelids, has recently been described [135], but needs of course to be further evaluated in larger series of patients and with longer follow-ups.

Palmoplantar keratoderma, often with fissures and stiffness of the fingers, usually improves during oral retinoid therapy, although sometimes with a bothersome peeling of the skin [51]. Topical treatment with keratolytics is often rather ineffective and may be impractical, especially when greasy creams and ointments are applied to the palms. Fungal infections should always be considered as an aggravating factor.

Hyperkeratosis of the scalp and ear canals is notoriously difficult to treat without vigorous mechanical removal of the scales. This can be accomplished either by overnight 
application of a potent keratolytic agent on the scalp, followed by vigorous cleansing, or by regular microscopic rinsing of the ear canals with the help of an ear specialist. However, better therapies are needed for this common problem, particularly in patients with LI.

\section{Conclusions}

Today, a molecular diagnosis is increasingly feasible in patients with ichthyosis and is a sine qua non for giving correct genetic advice and information about prognosis and treatment. This holds true also for young adult patients with the mildest forms of epidermolytic ichthyosis and ARCI, which in future offspring may cause serious perinatal morbidity.

Hopefully, a rapidly expanding knowledge about the skin barrier pathophysiology in ichthyosis will soon lead to new and more adaptable treatment options for patients who have these life-long and often incapacitating diseases. To further improve the quality of life of patients with ichthyosis, various psychosocial and practical aspects of daily life should also be addressed by future research.

Acknowledgements We would like to thank Susan Cure for critical comments on the manuscript.

\section{Compliance with Ethical Standards}

Conflict of interest AV is the Editor of Acta Dermatovenereologica. JF and HT have no conflicts of interest to declare.

Funding No funding was received for the preparation of this review.

Open Access This article is distributed under the terms of the Creative Commons Attribution-NonCommercial 4.0 International License (http://creativecommons.org/licenses/by-nc/4.0/), which permits any noncommercial use, distribution, and reproduction in any medium, provided you give appropriate credit to the original author(s) and the source, provide a link to the Creative Commons license, and indicate if changes were made.

\section{References}

1. Oji V, Traupe H. Ichthyosis: clinical manifestations and practical treatment options. Am J Clin Dermatol. 2009;10(6):351-64.

2. Brown SJ, Relton CL, Liao H, Zhao Y, Sandilands A, McLean $\mathrm{WH}$, et al. Filaggrin haploinsufficiency is highly penetrant and is associated with increased severity of eczema: further delineation of the skin phenotype in a prospective epidemiological study of 792 school children. Br J Dermatol. 2009;161(4):884-9.

3. Oji V, Tadini G, Akiyama M, Blanchet Bardon C, Bodemer C, Bourrat E, et al. Revised nomenclature and classification of inherited ichthyoses: results of the First Ichthyosis Consensus Conference in Soreze 2009. J Am Acad Dermatol. 2010;63(4):607-41.
4. Dreyfus I, Pauwels C, Bourrat E, Bursztejn AC, Maruani A, Chiaverini C, et al. Burden of inherited ichthyosis: a French national survey. Acta Derm Venereol. 2015;95(3):326-8.

5. Schmuth M, Gruber R, Elias PM, Williams ML. Ichthyosis update: towards a function-driven model of pathogenesis of the disorders of cornification and the role of corneocyte proteins in these disorders. Adv Dermatol. 2007;23:231-56.

6. Kuramoto N, Takizawa T, Matsuki M, Morioka H, Robinson JM, Yamanishi K. Development of ichthyosiform skin compensates for defective permeability barrier function in mice lacking transglutaminase 1. J Clin Invest. 2002;109(2):243-50.

7. Ishida-Yamamoto A, Igawa S. The biology and regulation of corneodesmosomes. Cell Tissue Res. 2015;360(3):477-82.

8. Feingold KR, Elias PM. Role of lipids in the formation and maintenance of the cutaneous permeability barrier. Biochim Biophys Acta. 2014;1841(3):280-94.

9. Raymond AA, Gonzalez de Peredo A, Stella A, Ishida-Yamamoto A, Bouyssie D, Serre G, et al. Lamellar bodies of human epidermis: proteomics characterization by high throughput mass spectrometry and possible involvement of CLIP-170 in their trafficking/secretion. Mol Cell Proteomics. 2008;7(11):2151-75.

10. Elias PM, Williams ML, Maloney ME, Bonifas JA, Brown BE, Grayson S, et al. Stratum corneum lipids in disorders of cornification. Steroid sulfatase and cholesterol sulfate in normal desquamation and the pathogenesis of recessive X-linked ichthyosis. J Clin Invest. 1984;74(4):1414-21.

11. Sato J, Denda M, Nakanishi J, Nomura J, Koyama J. Cholesterol sulfate inhibits proteases that are involved in desquamation of stratum corneum. J Invest Dermatol. 1998;111(2):189-93.

12. Hoppe T, Winge MC, Bradley M, Nordenskjöld M, Vahlquist A, Berne B, et al. X-linked recessive ichthyosis: an impaired barrier function evokes limited gene responses before and after moisturizing treatments. Br J Dermatol. 2012;167(3):514-22.

13. Winge MC, Hoppe T, Berne B, Vahlquist A, Nordenskjold M, Bradley $\mathrm{M}$, et al. Filaggrin genotype determines functional and molecular alterations in skin of patients with atopic dermatitis and ichthyosis vulgaris. PLoS One. 2011;6(12):e28254.

14. Sturesdotter Hoppe T. Skin barrier function and mRNA expression profiles in patients with atopic dermatitis, ichthyosis vulgaris, and X-linked recessive ichthyosis: aetiopathogenic differences and the impact of moisturizing treatment. Digital comprehensive summaries of Uppsala dissertations from the Faculty of Medicine, ISSN 1651-6206; 859. Uppsala: Uppsala University; 2013.

15. Paller AS, Renert-Yuval Y, Suprun M, Esaki H, Oliva M, Huynh $\mathrm{TN}$, et al. An IL-17-dominant immune profile is shared across the major orphan forms of ichthyosis. J Allergy Clin Immunol. 2017;139(1):152-65.

16. Khnykin D, Ronnevig J, Johnsson M, Sitek JC, Blaas HG, Hausser I, et al. Ichthyosis prematurity syndrome: clinical evaluation of 17 families with a rare disorder of lipid metabolism. J Am Acad Dermatol. 2012;66(4):606-16.

17. Hellström Pigg M, Bygum A, Ganemo A, Virtanen M, Brandrup $\mathrm{F}$, Zimmer AD, et al. Spectrum of autosomal recessive congenital ichthyosis in Scandinavia: clinical characteristics and novel and recurrent mutations in 132 patients. Acta Derm Venereol. 2016;96(7):932-7.

18. Moskowitz DG, Fowler AJ, Heyman MB, Cohen SP, Crumrine $\mathrm{D}$, Elias PM, et al. Pathophysiologic basis for growth failure in children with ichthyosis: an evaluation of cutaneous ultrastructure, epidermal permeability barrier function, and energy expenditure. J Pediatr. 2004;145(1):82-92.

19. Chan A, Godoy-Gijon E, Nuno-Gonzalez A, Crumrine D, Hupe $\mathrm{M}$, Choi EH, et al. Cellular basis of secondary infections and 
impaired desquamation in certain inherited ichthyoses. JAMA Dermatol. 2015;151(3):285-92.

20. Haneda T, Imai Y, Uchiyama R, Jitsukawa O, Yamanishi K. Activation of molecular signatures for antimicrobial and innate defense responses in skin with transglutaminase 1 deficiency. PLoS One. 2016;11(7):e0159673.

21. Schmuth M, Martinz V, Janecke AR, Fauth C, Schossig A, Zschocke $\mathrm{J}$, et al. Inherited ichthyoses/generalized Mendelian disorders of cornification. Eur J Hum Genet. 2013;21(2):123-33.

22. Marukian NV, Choate KA. Recent advances in understanding ichthyosis pathogenesis. F1000Res. 2016;5(F1000 Faculty Rev): 1497.

23. McLean WH. Filaggrin failure-from ichthyosis vulgaris to atopic eczema and beyond. Br J Dermatol. 2016;175(Suppl 2):4-7.

24. Lavrijsen AP, Oestmann E, Hermans J, Bodde HE, Vermeer BJ, Ponec M. Barrier function parameters in various keratinization disorders: transepidermal water loss and vascular response to hexyl nicotinate. Br J Dermatol. 1993;129(5):547-53.

25. Smith FJ, Irvine AD, Terron-Kwiatkowski A, Sandilands A, Campbell LE, Zhao Y, et al. Loss-of-function mutations in the gene encoding filaggrin cause ichthyosis vulgaris. Nat Genet. 2006;38(3):337-42.

26. Nomura T, Akiyama M, Sandilands A, Nemoto-Hasebe I, Sakai $\mathrm{K}$, Nagasaki A, et al. Specific filaggrin mutations cause ichthyosis vulgaris and are significantly associated with atopic dermatitis in Japan. J Invest Dermatol. 2008;128(6):1436-41.

27. Sinclair C, O'Toole EA, Paige D, El Bashir H, Robinson J, Dobson R, et al. Filaggrin mutations are associated with ichthyosis vulgaris in the Bangladeshi population. Br J Dermatol. 2009;160(5):1113-5.

28. Brown SJ, McLean WH. One remarkable molecule: filaggrin. J Invest Dermatol. 2012;132(3 Pt 2):751-62.

29. Kirchmeier P, Zimmer A, Bouadjar B, Rosler B, Fischer J. Whole-exome-sequencing reveals small deletions in CASP14 in patients with autosomal recessive inherited ichthyosis. Acta Derm Venereol. 2017;97(1):102-4.

30. Hoste E, Kemperman P, Devos M, Denecker G, Kezic S, Yau N, et al. Caspase-14 is required for filaggrin degradation to natural moisturizing factors in the skin. $J$ Invest Dermatol. 2011;131(11):2233-41.

31. Vahlquist A. Pleomorphic ichthyosis: proposed name for a heterogeneous group of congenital ichthyoses with phenotypic shifting and mild residual scaling. Acta Derm Venereol. 2010;90(5):454-60.

32. Zuo Y, Zhuang DZ, Han R, Isaac G, Tobin JJ, McKee M, et al. ABCA12 maintains the epidermal lipid permeability barrier by facilitating formation of ceramide linoleic esters. J Biol Chem. 2008;283(52):36624-35.

33. Russell LJ, DiGiovanna JJ, Rogers GR, Steinert PM, Hashem N, Compton JG, et al. Mutations in the gene for transglutaminase 1 in autosomal recessive lamellar ichthyosis. Nat Genet. 1995;9(3):279-83.

34. Lefevre C, Audebert S, Jobard F, Bouadjar B, Lakhdar H, Boughdene-Stambouli $\mathrm{O}$, et al. Mutations in the transporter ABCA12 are associated with lamellar ichthyosis type 2. Hum Mol Genet. 2003;12(18):2369-78.

35. Lefevre C, Bouadjar B, Ferrand V, Tadini G, Megarbane A, Lathrop M, et al. Mutations in a new cytochrome P450 gene in lamellar ichthyosis type 3. Hum Mol Genet. 2006;15(5):767-76.

36. Jobard F, Lefevre C, Karaduman A, Blanchet-Bardon C, Emre $\mathrm{S}$, Weissenbach J, et al. Lipoxygenase-3 (ALOXE3) and 12(R)lipoxygenase (ALOX12B) are mutated in non-bullous congenital ichthyosiform erythroderma (NCIE) linked to chromosome 17p13.1. Hum Mol Genet. 2002;11(1):107-13.
37. Lefevre C, Bouadjar B, Karaduman A, Jobard F, Saker S, Ozguc $\mathrm{M}$, et al. Mutations in ichthyin a new gene on chromosome $5 \mathrm{q} 33$ in a new form of autosomal recessive congenital ichthyosis. Hum Mol Genet. 2004;13(20):2473-82.

38. Radner FP, Marrakchi S, Kirchmeier P, Kim GJ, Ribierre F, Kamoun B, et al. Mutations in CERS3 cause autosomal recessive congenital ichthyosis in humans. PLoS Genet. 2013;9(6):e1003536.

39. Eckl KM, Tidhar R, Thiele H, Oji V, Hausser I, Brodesser S, et al. Impaired epidermal ceramide synthesis causes autosomal recessive congenital ichthyosis and reveals the importance of ceramide acyl chain length. J Invest Dermatol. 2013;133(9):2202-11.

40. Jennemann R, Rabionet M, Gorgas K, Epstein S, Dalpke A, Rothermel U, et al. Loss of ceramide synthase 3 causes lethal skin barrier disruption. Hum Mol Genet. 2012;21(3):586-608.

41. Shigehara Y, Okuda S, Nemer G, Chedraoui A, Hayashi R, Bitar $\mathrm{F}$, et al. Mutations in SDR9C7 gene encoding an enzyme for vitamin A metabolism underlie autosomal recessive congenital ichthyosis. Hum Mol Genet. 2016;25(20):4484-93.

42. Grall A, Guaguere E, Planchais S, Grond S, Bourrat E, Hausser I, et al. PNPLA1 mutations cause autosomal recessive congenital ichthyosis in golden retriever dogs and humans. Nat Genet. 2012;44(2):140-7.

43. Vahidnezhad H, Youssefian L, Saeidian AH, Zeinali S, Mansouri $\mathrm{P}$, Sotoudeh $\mathrm{S}$, et al. Gene targeted next generation sequencing identifies PNPLA1 mutations in patients with a phenotypic spectrum of autosomal recessive congenital ichthyosis: the impact of consanguinity. J Invest Dermatol. 2017;137(3):678-85.

44. Zimmer AD, Kim GJ, Hotz A, Bourrat E, Hausser I, Has C, et al. Sixteen Novel mutations in PNPLA1 in patients with autosomal recessive congenital ichthyosis reveal the importance of an extended patatin domain in PNPLA1 that is essential for proper human skin barrier function. Br J Dermatol. 2017. doi:10.1111/ bjd. 15308 .

45. Klar J, Schweiger M, Zimmerman R, Zechner R, Li H, Törmä $\mathrm{H}$, et al. Mutations in the fatty acid transport protein 4 gene cause the ichthyosis prematurity syndrome. Am J Hum Genet. 2009;85(2):248-53.

46. Israeli S, Khamaysi Z, Fuchs-Telem D, Nousbeck J, Bergman R, Sarig O, et al. A mutation in LIPN, encoding epidermal lipase N, causes a late-onset form of autosomal-recessive congenital ichthyosis. Am J Hum Genet. 2011;88(4):482-7.

47. Aldahmesh MA, Mohamed JY, Alkuraya HS, Verma IC, Puri RD, Alaiya AA, et al. Recessive mutations in ELOVL4 cause ichthyosis, intellectual disability, and spastic quadriplegia. Am J Hum Genet. 2011;89(6):745-50.

48. McMahon A, Butovich IA, Kedzierski W. Epidermal expression of an Elovl4 transgene rescues neonatal lethality of homozygous Stargardt disease-3 mice. J Lipid Res. 2011;52(6):1128-38.

49. Vasireddy V, Uchida Y, Salem N Jr, Kim SY, Mandal MN, Reddy GB, et al. Loss of functional ELOVL4 depletes very long-chain fatty acids $(\geq \mathrm{C} 28)$ and the unique omega- $O$-acylceramides in skin leading to neonatal death. Hum Mol Genet. 2007;16(5):471-82.

50. Ohno Y, Nakamichi S, Ohkuni A, Kamiyama N, Naoe A, Tsujimura $\mathrm{H}$, et al. Essential role of the cytochrome P450 CYP4F22 in the production of acylceramide, the key lipid for skin permeability barrier formation. Proc Natl Acad Sci USA. 2015;112(25):7707-12.

51. Grond S, Eichmann TO, Dubrac S, Kolb D, Schmuth M, Fischer $\mathrm{J}$, et al. PNPLA1 deficiency in mice and humans leads to a defect in the synthesis of omega- $O$-acylceramides. J Invest Dermatol. 2017;137(2):394-402. 
52. Dick A, Tantcheva-Poor I, Oji V, Giehl KA, Fischer J, Krieg P et al. Diminished protein-bound omega-hydroxylated ceramides in the skin of ichthyosis patients with 12r-Lox or Elox-3 deficiency. Br J Dermatol. 2017. doi:10.1111/bjd.15406.

53. Takagi Y, Nakagawa H, Kondo H, Takema Y, Imokawa G. Decreased levels of covalently bound ceramide are associated with ultraviolet B-induced perturbation of the skin barrier. J Invest Dermatol. 2004;123(6):1102-9.

54. Zhang L, Ferreyros M, Feng W, Hupe M, Crumrine DA, Chen J, et al. Defects in stratum corneum desquamation are the predominant effect of impaired ABCA12 function in a novel mouse model of harlequin ichthyosis. PLoS One. 2016;11(8):e0161465.

55. Gruber R, Rainer G, Weiss A, Udvardi A, Thiele H, Eckl KM, et al. Morphological alterations in two siblings with autosomal recessive congenital ichthyosis associated with CYP4F22 mutations. Br J Dermatol. 2017;176(4):1068-73.

56. Lin MH, Miner JH. Fatty acid transport protein 1 can compensate for fatty acid transport protein 4 in the developing mouse epidermis. J Invest Dermatol. 2015;135(2):462-70.

57. Schmuth M, Ortegon AM, Mao-Qiang M, Elias PM, Feingold KR, Stahl A. Differential expression of fatty acid transport proteins in epidermis and skin appendages. J Invest Dermatol. 2005; 125(6):1174-81.

58. Li H, Vahlquist A, Törmä H. Interactions between FATP4 and ichthyin in epidermal lipid processing may provide clues to the pathogenesis of autosomal recessive congenital ichthyosis. J Dermatol Sci. 2013;69(3):195-201.

59. Hirabayashi T, Anjo T, Kaneko A, Senoo Y, Shibata A, Takama $\mathrm{H}$, et al. PNPLA1 has a crucial role in skin barrier function by directing acylceramide biosynthesis. Nat Commun. 2017;8:14609.

60. Ohno Y, Kamiyama N, Nakamichi S, Kihara A. PNPLA1 is a transacylase essential for the generation of the skin barrier lipid omega- $O$-acylceramide. Nat Commun. 2017;8:14610.

61. Zheng Y, Yin H, Boeglin WE, Elias PM, Crumrine D, Beier DR, et al. Lipoxygenases mediate the effect of essential fatty acid in skin barrier formation: a proposed role in releasing omega-hydroxyceramide for construction of the corneocyte lipid envelope. J Biol Chem. 2011;286(27):24046-56.

62. Krieg P, Rosenberger S, de Juanes S, Latzko S, Hou J, Dick A, et al. Aloxe3 knockout mice reveal a function of epidermal lipoxygenase- 3 as hepoxilin synthase and its pivotal role in barrier formation. J Invest Dermatol. 2013;133(1):172-80.

63. Muñoz-Garcia A, Thomas CP, Keeney DS, Zheng Y, Brash AR. The importance of the lipoxygenase-hepoxilin pathway in the mammalian epidermal barrier. Biochimica et Biophysica Acta (BBA) Mole Cell Biol Lipids. 2014;1841(3):401-8.

64. Vahlquist A, Bygum A, Gånemo A, Virtanen M, Hellström-Pigg M, Strauss G, et al. Genotypic and clinical spectrum of selfimproving collodion ichthyosis: ALOX12B, ALOXE3, and TGM1 mutations in Scandinavian patients. J Invest Dermatol. 2010;130(2):438-43.

65. Peterson LL, Wuepper KD. Epidermal and hair follicle transglutaminases and crosslinking in skin. Mol Cell Biochem. 1984;58(1-2):99-111.

66. Candi E, Melino G, Mei G, Tarcsa E, Chung SI, Marekov LN, et al. Biochemical, structural, and transglutaminase substrate properties of human loricrin, the major epidermal cornified cell envelope protein. J Biol Chem. 1995;270(44):26382-90.

67. Nemes Z, Marekov LN, Fesus L, Steinert PM. A novel function for transglutaminase 1: attachment of long-chain omega-hydroxyceramides to involucrin by ester bond formation. Proc Natl Acad Sci USA. 1999;96(15):8402-7.

68. Elias PM, Schmuth M, Uchida Y, Rice RH, Behne M, Crumrine $\mathrm{D}$, et al. Basis for the permeability barrier abnormality in lamellar ichthyosis. Exp Dermatol. 2002;11(3):248-56.
69. Dahlqvist J, Klar J, Hausser I, Anton-Lamprecht I, Hellström Pigg M, Gedde-Dahl T Jr, et al. Congenital ichthyosis: mutations in ichthyin are associated with specific structural abnormalities in the granular layer of epidermis. J Med Genet. 2007;44(10):615-20.

70. Mauldin EA, Wang P, Evans E, Cantner CA, Ferracone JD, Credille KM, et al. Autosomal recessive congenital ichthyosis in American Bulldogs is associated with NIPAL4 (ICHTHYIN) deficiency. Vet Pathol. 2015;52(4):654-62.

71. Dahlqvist J, Westermark GT, Vahlquist A, Dahl N. Ichthyin/ NIPAL4 localizes to keratins and desmosomes in epidermis and Ichthyin mutations affect epidermal lipid metabolism. Arch Dermatol Res. 2012;304(5):377-86.

72. Li H, Pavez Loriè E, Fisher J, Vahlquist A, Törmä H. The expression of epidermal lipoxygenases and transglutaminase-1 is perturbed by NIPAL4 mutations: indications of a common metabolic pathway essential for skin barrier homeostasis. J Invest Dermatol. 2012;132:2368-75.

73. Lin MH, Khnykin D. Fatty acid transporters in skin development, function and disease. Biochim Biophys Acta. 2014;1841(3):362-8.

74. Takeichi T, Nomura T, Takama H, Kono M, Sugiura K, Watanabe D, et al. Deficient stratum corneum intercellular lipid in a Japanese patient with lamellar ichthyosis by a homozygous deletion mutation in SDR9C7. Br J Dermatol. 2017. doi:10. 1111/bjd.15315.

75. Kowalik D, Haller F, Adamski J, Moeller G. In search for function of two human orphan SDR enzymes: hydroxysteroid dehydrogenase like 2 (HSDL2) and short-chain dehydrogenase/ reductase-orphan (SDR-O). J Steroid Biochem Mol Biol. 2009;117(4-5):117-24.

76. Traupe H, Fischer J, Oji V. Nonsyndromic types of ichthyosesan update. J Dtsch Dermatol Ges. 2014;12(2):109-21.

77. Hotz A, Oji V, Bourrat E, Jonca N, Mazereeuw-Hautier J, Betz $\mathrm{RC}$, et al. Expanding the clinical and genetic spectrum of KRT1, KRT2 and KRT10 mutations in keratinopathic ichthyosis. Acta Derm Venereol. 2016;96:473-8.

78. Lim YH, Choate KA. Expanding the mutation spectrum of ichthyosis with confetti. J Invest Dermatol. 2016;136(10): 1941-3.

79. Bygum A, Virtanen M, Brandrup F, Gånemo A, Sommerlund M, Strauss G, et al. Generalized and naevoid epidermolytic ichthyosis in Denmark: clinical and mutational findings. Acta Derm Venereol. 2013;93(3):309-13.

80. Anton-Lamprecht I. Ultrastructural identification of basic abnormalities as clues to genetic disorders of the epidermis. J Invest Dermatol. 1994;103(5 Suppl):6S-12S.

81. Chamcheu JC, Pihl-Lundin I, Mouyobo CE, Gester T, Virtanen M, Moustakas A, et al. Immortalized keratinocytes derived from patients with epidermolytic ichthyosis reproduce the disease phenotype: a useful in vitro model for testing new treatments. $\mathrm{Br}$ J Dermatol. 2011;164(2):263-72.

82. Schmuth M, Yosipovitch G, Williams ML, Weber F, Hintner H, Ortiz-Urda S, et al. Pathogenesis of the permeability barrier abnormality in epidermolytic hyperkeratosis. J Invest Dermatol. 2001;117(4):837-47.

83. Takeichi T, Akiyama M. Inherited ichthyosis: non-syndromic forms. J Dermatol. 2016;43(3):242-51.

84. Ezzedine K, Droitcourt C, Ged C, Diallo A, Hubiche T, de Verneuil $\mathrm{H}$, et al. Usefulness of a global clinical ichthyosis vulgaris scoring system for predicting common FLG null mutations in an adult caucasian population. $\mathrm{Br} \mathrm{J}$ Dermatol. 2012;167(5):1165-9.

85. Gånemo A, Pigg M, Virtanen M, Kukk T, Raudsepp H, Rossman-Ringdahl I, et al. Autosomal recessive congenital ichthyosis in Sweden and Estonia: clinical, genetic and 
ultrastructural findings in eighty-three patients. Acta Derm Venereol. 2003;83(1):24-30.

86. Vahlquist A, Blockhuys S, Steijlen P, van Rossem K, Didona B, Blanco D, et al. Oral liarozole in the treatment of patients with moderate/severe lamellar ichthyosis: results of a randomized, double-blind, multinational, placebo-controlled phase II/III trial. Br J Dermatol. 2014;170(1):173-81.

87. Tadini G, Giustini S, Milani M. Efficacy of topical $10 \%$ ureabased lotion in patients with ichthyosis vulgaris: a two-center, randomized, controlled, single-blind, right-vs.-left study in comparison with standard glycerol-based emollient cream. Curr Med Res Opin. 2011;27(12):2279-84.

88. DiGiovanna JJ, Bale SJ. Clinical heterogeneity in epidermolytic hyperkeratosis. Arch Dermatol. 1994;130(8):1026-35.

89. Choate KA, Lu Y, Zhou J, Choi M, Elias PM, Farhi A, et al. Mitotic recombination in patients with ichthyosis causes reversion of dominant mutations in KRT10. Science. 2010;330 (6000):94-7.

90. Diociaiuti A, Fortugno P, El Hachem M, Angelo C, Proto V, De Luca N, et al. Early immunopathological diagnosis of ichthyosis with confetti in two sporadic cases with new mutations in keratin 10. Acta Derm Venereol. 2014;94(5):579-82.

91. Lin TK, Crumrine D, Ackerman LD, Santiago JL, Roelandt T, Uchida Y, et al. Cellular changes that accompany shedding of human corneocytes. J Invest Dermatol. 2012;132(10):2430-9.

92. Elias PM, Williams ML, Crumrine D, Schmuth M. Inherited disorders of corneocyte proteins. In: Ichthyoses: clinical, biochemical, pathogenic and diagnostic assessment, Current problems in dermatology. vol. 39. Basel: Karger; 2010. p. 98-131.

93. Elias PM, Williams ML, Crumrine D, Schmuth M. Inherited disorders of accelerated desquamation. In: Ichthyoses: clinical, biochemical, pathogenic and diagnostic assessment, Current problems in dermatology, vol. 39. Basel: Karger; 2010. p. 89-97.

94. Elias PM, Williams ML, Crumrine D, Schmuth M. Inherited clinical disorders of lipid metabolism. In: Ichthyoses: clinical, biochemical, pathogenic and diagnostic assessment, Current problems in dermatology, vol. 39. Basel: Karger; 2010. p. 30-88.

95. Elias PM, Williams ML, Crumrine D, Schmuth M. Focuses solely on generalized, inherited (Mendelian) disorders of cornification (DOC or MeDOC). Introduction. In: Ichthyoses: clinical, biochemical, pathogenic and diagnostic assessment, Current problems in dermatology, vol. 39. Basel: Karger; 2010. p. 1-29.

96. Schlipf NA, Vahlquist A, Teigen N, Virtanen M, Dragomir A, Fismen S, et al. Whole-exome sequencing identifies novel autosomal recessive DSG1 mutations associated with mild SAM syndrome. Br J Dermatol. 2016;174(2):444-8.

97. Eckl KM, de Juanes S, Kurtenbach J, Natebus M, Lugassy J, Oji $\mathrm{V}$, et al. Molecular analysis of 250 patients with autosomal recessive congenital ichthyosis: evidence for mutation hotspots in ALOXE3 and allelic heterogeneity in ALOX12B. J Invest Dermatol. 2009;129(6):1421-8.

98. Fischer J. Autosomal recessive congenital ichthyosis. J Invest Dermatol. 2009;129(6):1319-21.

99. Raghunath M, Hennies HC, Ahvazi B, Vogel M, Reis A, Steinert PM, et al. Self-healing collodion baby: a dynamic phenotype explained by a particular transglutaminase-1 mutation. J Invest Dermatol. 2003;120(2):224-8.

100. Akbari MT, Ataei-Kachoui M. Triallelic inheritance of TGM1 and ALOXE3 mutations associated with severe phenotype of ichtyosis in an Iranian family - a case report. Iran J Public Health. 2015;44(7):1004-7.

101. Hernandez-Martin A, Aranegui B, Martin-Santiago A, GarciaDoval I. A systematic review of clinical trials of treatments for the congenital ichthyoses, excluding ichthyosis vulgaris. J Am Acad Dermatol. 2013;69(4):544-9 e8.

102. Vahlquist A, Gånemo A, Virtanen M. Congenital ichthyosis: an overview of current and emerging therapies. Acta Derm Venereol. 2008;88(1):4-14.

103. Vahlquist A. Treatment of rare keratinization disorders: what's new? Expert Rev Dermatol. 2011;6:211-6.

104. Gånemo A, Virtanen M, Vahlquist A. Improved topical treatment of lamellar ichthyosis: a double-blind study of four different cream formulations. Br J Dermatol. 1999;141(6):1027-32.

105. Williams ML, Elias PM. Enlightened therapy of the disorders of cornification. Clin Dermatol. 2003;21(4):269-73.

106. Ramirez ME, Youseef WF, Romero RG, Martinez JM, Gonzalez-Ensenat MA, Vilaplana XS, et al. Acute percutaneous lactic acid poisoning in a child. Pediatr Dermatol. 2006;23(3):282-5.

107. Bassotti A, Moreno S, Criado E. Successful treatment with topical $N$-acetylcysteine in urea in five children with congenital lamellar ichthyosis. Pediatr Dermatol. 2011;28(4):451-5.

108. Davila-Seijo P, Florez A, Davila-Pousa C, No N, Ferreira C, De la Torre C. Topical $\mathrm{N}$-acetylcysteine for the treatment of lamellar ichthyosis: an improved formula. Pediatr Dermatol. 2014;31(3):395-7.

109. Craiglow BG, Choate KA, Milstone LM. Topical tazarotene for the treatment of ectropion in ichthyosis. JAMA Dermatol. 2013;149(5):598-600.

110. Nguyen V, Cunningham BB, Eichenfield LF, Alio AB, Buka RL. Treatment of ichthyosiform diseases with topically applied tazarotene: risk of systemic absorption. J Am Acad Dermatol. 2007;57(5 Suppl):S123-5.

111. Lucker GP, van de Kerkhof PC, van Dijk MR, Steijlen PM. Effect of topical calcipotriol on congenital ichthyoses. Br J Dermatol. 1994;131(4):546-50.

112. Bogenrieder T, Landthaler M, Stolz W. Bullous congenital ichthyosiform erythroderma: safe and effective topical treatment with calcipotriol ointment in a child. Acta Derm Venereol. 2003;83(1):52-4.

113. Thacher TD, Fischer PR, Pettifor JM, Darmstadt GL. Nutritional rickets in ichthyosis and response to calcipotriene. Pediatrics. 2004;114(1):e119-23.

114. Gånemo A, Sommerlund M, Vahlquist A. Oral alitretinoin in congenital ichthyosis: a pilot study shows variable effects and a risk of central hypothyroidism. Acta Derm Venereol. 2012;92(3):256-7.

115. Vahlquist A, Törmä H. Retinoids and keratinization. Current concepts. Int J Dermatol. 1988;27(2):81-95.

116. DiGiovanna JJ, Mauro T, Milstone LM, Schmuth M, Toro JR. Systemic retinoids in the management of ichthyoses and related skin types. Dermatol Ther. 2013;26(1):26-38.

117. Pavez Lorie E, Ganemo A, Borgers M, Wouters L, Blockhuys S, van de Plassche L, et al. Expression of retinoid-regulated genes in lamellar ichthyosis vs. healthy control epidermis: changes after oral treatment with liarozole. Acta Derm Venereol. 2009;89(1):12-20.

118. Törmä H. Regulation of keratin expression by retinoids. Dermato Endocrinol. 2011;3(3):136-40.

119. Virtanen M, Törmä H, Vahlquist A. Keratin 4 upregulation by retinoic acid in vivo: a sensitive marker for retinoid bioactivity in human epidermis. J Invest Dermatol. 2000;114(3):487-93.

120. Virtanen M, Gedde-Dahl T Jr, Mork NJ, Leigh I, Bowden PE, Vahlquist A. Phenotypic/genotypic correlations in patients with epidermolytic hyperkeratosis and the effects of retinoid therapy on keratin expression. Acta Derm Venereol. 2001;81(3):163-70.

121. Okano M, Kitano Y, Yoshikawa K. A trial of oral 1 alpha-hydroxyvitamin D3 for ichthyosis. Dermatologica. 1988;177(1):23.

122. Sethuraman G, Marwaha RK, Challa A, Yenamandra VK, Ramakrishnan L, Thulkar S, et al. Vitamin D: a new promising therapy for congenital ichthyosis. Pediatrics. 2016;137(1):1-5. 
123. Chouhan K, Sethuraman G, Gupta N, Sharma VK, Kabra M, Khaitan BK, et al. Vitamin D deficiency and rickets in children and adolescents with ichthyosiform erythroderma in type IV and V skin. Br J Dermatol. 2012;166(3):608-15.

124. Neema S, Mukherjee S, Vasudevan B, Verma R, Moorchung N, Chatterjee M. Vitamin D deficiency after oral retinoid therapy for ichthyosis. Pediatr Dermatol. 2015;32(4):e151-5.

125. Esterly NB, Maxwell E. Nonbullous congenital ichthyosiform erythroderma: a case treated with methotrexate. Pediatrics. 1968;41(1):120-2.

126. O'Shaughnessy RF, Choudhary I, Harper JI. Interleukin-1 alpha blockade prevents hyperkeratosis in an in vitro model of lamellar ichthyosis. Hum Mol Genet. 2010;19(13):2594-605.

127. Cottle DL, Ursino GM, Ip SC, Jones LK, Ditommaso T, Hacking DF, et al. Fetal inhibition of inflammation improves disease phenotypes in harlequin ichthyosis. Hum Mol Genet. 2015;24(2):436-49.

128. Aufenvenne K, Rice RH, Hausser I, Oji V, Hennies HC, Rio $\mathrm{MD}$, et al. Long-term faithful recapitulation of transglutaminase 1-deficient lamellar ichthyosis in a skin-humanized mouse model, and insights from proteomic studies. J Invest Dermatol. 2012;132(7):1918-21.

129. Aufenvenne K, Larcher F, Hausser I, Duarte B, Oji V, Nikolenko $\mathrm{H}$, et al. Topical enzyme-replacement therapy restores transglutaminase 1 activity and corrects architecture of transglutaminase-1-deficient skin grafts. Am J Hum Genet. 2013;93(4):620-30.

130. Khavari PA, Rollman O, Vahlquist A. Cutaneous gene transfer for skin and systemic diseases. J Intern Med. 2002;252(1):1-10.

131. Abdul-Wahab A, Qasim W, McGrath JA. Gene therapies for inherited skin disorders. Semin Cutan Med Surg. 2014;33(2):83-90.

132. Dyer JA, Spraker M, Williams M. Care of the newborn with ichthyosis. Dermatol Ther. 2013;26(1):1-15.

133. Haenssle HA, Finkenrath A, Hausser I, Oji V, Traupe H, Hennies $\mathrm{HC}$, et al. Effective treatment of severe thermodysregulation by oral retinoids in a patient with recessive congenital lamellar ichthyosis. Clin Exp Dermatol. 2008;33(5):578-81.

134. Washio K, Fukunaga A, Terai M, Hitomi K, Yamanishi K, Nishigori C. Hypohidrosis plays a crucial role in the vicious circle of bathing suit ichthyosis: a case with summer exacerbation. Acta Derm Venereol. 2014;94(3):349-50.

135. Sigurdsson H, Baldursson BT. Inverting sutures with systemic retinoids and lubrication can correct ectropion in ichthyosis. Ophthal Plast Reconstr Surg. 2016;32(5):e112-3. 